\title{
Denetimde Standartlaşma Çabalart: Motorlu Taşıt Sürücüleri Kursu Denetim Rehberi Örneği
}

\author{
Doç. Dr. Nedim Özdemir \\ Ege Üniversitesi-Türkiye \\ nedim.ozdemir@ege.edu.tr
}

\author{
Fahri Altuntaş \\ Izmir il Milli Eğitim Müdürlüğü-Türkiye \\ faltuntas44@gmail.com
}

\begin{abstract}
Özet:
Bu araştırmanın amacı, denetimde uygulama birliği ve standartlaşmayı sağlamak üzere hazırlanmış motorlu taşıtlar sürücü kursu denetim rehberinin temel bölümlerinin eğitim denetimi alanyazını ve yasal mevzuata göre tutarlı̆̆ının incelenmesidir. Çalışmada, nitel araştırma yaklaşımı benimsenmiş olup doküman analizi tekniği kullanılmıştır. Bu doğrultuda Milli Eğitim Bakanlığı tarafından maarif müfettişleri başkanlıkları için oluşturulan denetim rehberleri içerisinden motorlu taşıtlar sürücü kursları için hazırlanan doküman incelenmiştir. Araştırmanın verileri doküman analizi tekniğine göre çözümlenmiş ve elde edilen bulgular "Denetim Rehberinin Yasal Belgelerle ilişkisi" ve "Denetim Rehberinin Alanyazınla ilişkisi" olmak üzere iki tema altında sunulmuştur. Araştırmanın sonuçları, rehberdeki ifadeler ile yasal dayanağın çoğunlukla örtüştüğünü göstermiştir. Öte yandan, yasal dayanağa göre rehberde eksik ifade edilmiş maddeler de bulunmaktadır. Ayrıca, denetim rehberinin yayımlanmasından sonra yasal belgeler üzerinde yapılan güncellemelerin bu rehbere yansıtılmadığı anlaşılmıştır. Denetim rehberindeki maddeler alanyazın açışından değerlendirildiğinde bazı maddeler için değerlendirme ölçütlerinin yer almadığı saptanmıştır. Araştırma kapsamında Milli Eğitim Bakanlığının ilgili yönetmeliklerde yaptığı düzenlemeleri denetim rehberine yansıtması önerilmiştir.
\end{abstract}

Keywords: Denetim, Denetim Rehberi, Denetimde Standardizasyon, Doküman Analizi, Motorlu Taşıt Sürücüleri Kursu

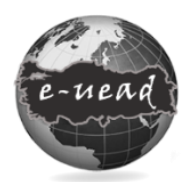

E-Uluslararası Eğitim

Araştırmaları Dergisi, Cilt: 11, Sayı: 3, 2020, ss.79-89

DOI: 10.19160/ijer.807767

\section{Önerilen Atıf}

Özdemir, N. \&. Altuntaş, F. (2020). Denetimde standartlaşma çabaları: Motorlu taşıt sürücüleri kursu denetim rehberi örneği, E-Uluslararası Eğitim Araştırmaları Dergisi, Cilt: 11, Sayı: 3, 2020, ss. 79-89, DOI: $10.19160 /$ ijer.807767 


\section{Giriş}

Eğitim denetimi, eğitimde gerçekleştirilen eylemlerin; mevcut yasal işleyişe, belirlenen amaca, hazırlanan plana, eldeki madde ve insan kaynaklarına uygun olup olmadığını kontrol etme sürecidir (Toprakçı, Çakırer, Bilbay, Bagcivan ve Bayraktutan, 2010). Denetim, eğitim kurumları arasındaki kalite farklılıklarını azaltmada ve kurumların temel standartlarını yerine getirmesinde önemli bir role sahiptir. Denetimin öğrenme çıktıları üzerinde etkili olduğunu gösteren kanıtlar (Liu, Xu ve Stronge, 2018; Tuytens ve Devos, 2017) ve eğitimde hesapverebilirlik tartışmaları (Tuytens ve Devos, 2017) bu farklılıkların azaltılmasını hedefleyen reformlara yeni bir ivme kazandırmıştır. Yönetim faaliyetleri sonucunda kurumların amaçlarına ne derece ulaştığını saptanmak ve iyileştirmeye açık alanlarını belirlenmek gerekmektedir. Bu kapsamda denetim sürecinde denetçinin bilgi birikimi, çalışanlara sunduğu dönütler ve onları mesleki öğrenmeye yönlendirmesi ön plana çıkmaktadır (Özdemir, 2020). Diğer taraftan, uygulamada her denetçinin bu özellikleri sergilemediği ve denetimde farklı sonuçlarının ortaya çıktığı görülmektedir (Kazak, 2013). Denetçiler arasında uygulama birliğini ve standartlaşmayı sağlamak üzere güvenirliği ve geçerliliği sağlanmış araçların nasıl hazırlanacağı ve kullanılacağı ise tartışılan bir konu olmaya devam etmektedir (Cohen ve Goldhaber, 2016; Heneman ve Milanowski, 2003). Nitekim denetime rehberlik edecek şekilde bilimsel temelde oluşturulan güvenilir ölçütlerin denetimin kalitesini ve eğitimde niteliği artırabildiği vurgulanmaktadır (Bitan, Haep ve Steins, 2015; Xin ve Kang, 2012).

Denetimin yapıldığı eğitim kurumlarından birisi de motorlu taşıt sürücüleri kurslarıdır. Bu kursları başarıyla tamamlamış bireyler sürücü olarak kabul edilmekte ve karayolu trafiğine çıkmalarına izin verilmektedir. Bu sürücülerin nitelikli eğitim alması ve bunun da denetlenmesi son derece önemlidir. Çünkü sürücülere verilen eğitimlerin niteliği ne kadar iyi ise karayollarında meydana gelen kazaların oranı da o kadar düşük olacaktır. Nitekim karayolları trafik kazaları insanların yaşam hakkını tehdit eden önemli sorunlardan birisi olmaya devam etmektedir. Bu kazalar, dünya genelinde her yıl yaklaşık bir milyon 340 bin ölüme (World Health Organization [WHO], 2016) ve çoğu yaşam boyu sakatlığa yol açacak biçimde yaklaşık 50 milyon ölümcül olmayan yaralanmayla sonuçlanmaktadır. Bu durum bireyler, aileler, sağlık sistemleri ve ekonomiler üzerinde ciddi bir yük oluşturmaktadır. Bu kazaların oluşumundaki nedenler sıralandığında ise en önemli faktörlerden birisinin sürücüler olduğu görülmektedir (Eygü, 2018). Özellikle 25 yaş altındaki sürücülerin sürüş becerisindeki yetersizlik dikkat çekicidir (Freydier, Berthelon ve Bastien-Toniazzo, 2016). Sürücü adaylarını yetiştirilmesinde önemli bir konumda olan kursların denetimi ile birlikte sunulan eğitimin niteliğinin artması beklenmektedir.

Motorlu taşıt sürücüleri kurslarına ilişkin yapılan çalışmalar, Türkiye ve Avrupa Birliği ülkelerinde sürücü eğitimi ve uygulama sınavlarının incelenmesi (Selbes, 2008; Süslü, Ernas ve Ergören, 2020), teorik ve elektronik sınavların cinsiyet, yaş, sertifika türü gibi değişkenlere göre karşılaştırılması (Doğru, 2018) ve kursların performanslarının değerlendirilmesi (Güleç, 2012) gibi konuları kapsadığı görülmektedir. Buna karşın alanyazında motorlu taşıt sürücü kurslarının denetimine ilişkin bir çalışmaya rastlanılmamıştır. Milli Eğitim Bakanlığı (MEB) motorlu taşıt sürücüleri kurslarının denetimi için uygulama birliğini ve standartlaşmayı sağlamak üzere bir rehber 
hazırlamıştır. Öte yandan, bu rehberin yasal belgeleri ve denetim alanyazınını ne düzeyde karşıladığı açık değildir. Nitekim Toprakçı ve Bakır (2019) tarafından yürütülen bir çalışmada yasal belgeler arasında bazı konularda yeterince uyumun olmadığı sonucuna ulaşılmıştır. Bu doğrultuda, motorlu taşıt sürücüleri kurslarının denetimine ilişkin oluşturulan rehberin yasal belgeler ve alanyazın ile karşılaştırması yapılarak uygulayıcılara güncel bilgiler sunması hedeflenmiştir. Ayrıca, bu çalışmadan elde edilecek bulguların rehberin güncellenmesi aşamasında politika yapıcılara kaynaklık etmesi beklenmektedir. Bu bölümde sırasıyla denetim ve motorlu taşıt sürücüleri kurslarına ilişkin kavramsal çerçeve sunulmuş ve araştırmanın amacına ve alt problemlerine yer verilmiştir.

\section{Denetim ve Standardizasyon}

Sözlük karşılığı "göz kulak olmak", "yönlendirmek", "nezaret etmek" (Glickman, Gordon ve Roos-Gordon, 2014) olan denetim, yönetim süreçlerinden biri olup faaliyetlerin izlenmesini ve gerektiğinde yeniden düzenlenmesine rehberlik etmektedir (Başar, 2000; Robbins, Decenzo ve Coulter, 2013). Denetimin yakın hedefi, örgütle ilgili her şeyin düzeltilip geliştirilmesidir. Ayrıca denetim sayesinde örgüt amaçlarının gerçekleşme düzeyi belirlenmiş olur. Denetim aynı zamanda amaçların, örgütün ve günün gereksinimlerine uygun bir şekilde gerçekleşmesine de yardımcı olmaktadır. Denetimin uzak hedefi ise örgüt çalışanlarını öz denetimli yapmaktır (Başar, 2000). Denetim, örgütte geçekleşen faaliyetlerin performansına ilişkin ölçme işleminin yapıldığı durum belirleme aşaması ile başlamaktadır (Başar, 2000). Etkili bir denetim için ölçme işleminin yapılması ve bir değerlendirmeye varılması gerekir (Hicks, 1979). Denetim için bir planın oluşturulması, denetlenecek kişilerle ön görüşmenin sağlanması ve gözlem-inceleme ile ölçme işleminin gerçekleşmesi sağlanmış olur. Bu aşamadaki nihai amaç kişilerin öz denetimli olmasına aracı olmaktır. Ölçüm sonucu önceden belirlenmiş bir standart ile karşılaştırılır ve bu standarda göre sapmalar düzeltilip geliştirilir (Toprakçı, 2013). Denetim sürecindeki standartlar, planlama sürecinde oluşturulan hedefleri kapsamaktadır (Robbins vd., 2013). Düzeltme ve geliştirme aşamasında ise değerlendirme sonuçları esas alınarak, değerlendirmede belirlenen eksikler tamamlanır, yanlışlıklar doğrularla yer değiştirir ve gereksiz fazlalıklar ortadan kaldırılır (Başar, 2000). Bu yüzden etkili bir denetim için denetçinin bilgi birikiminin yanı sıra iletişim becerileri ile teknik yeterliklere sahip olması beklenir (Glickman vd., 2014).

Son on yıl içerisinde Amerika (Lavigne ve Chamberlain, 2016; Lochmiller, 2016; Reid, 2019), Çin (Liu vd., 2018), İngiltere (Reynolds, Muijs ve Treharne, 2003) ve Belçika (Tuytens ve Devos, 2017) gibi dünyada birçok ülkede eğitim kurumlarının denetiminde önemli reformlarının yapıldığı görülmektedir. Bu reformların odağında ise standartlara dayalı değerlendirme yaklaşımı bulunmaktadır (Tuytens ve Devos, 2014). Denetimde standardizasyon, denetim faaliyetlerini düzenlemek amacıyla oluşturulmakta ve hem denetim işlerini yürüten kurumlar hem de denetçiler tarafından uyulması gereken davranış kurallarını ifade etmektedir (Liu, 2015). Başka bir çalışmada ise Timmermans ve Epstein (2010) standartlaşma sürecini (i) standartları oluşturma ve direnç, (ii) uygulama ve (iii) sonuçlar olmak üzere üç aşamada tanımlamışlardır. Bu yüzden standartları oluşturan kurumların bu standartların ne ölçüde karşılık bulduğunu, hangi yönlerinin eleştirildiğini, nasıl uygulandığını ve hangi sonuçları ürettiğini incelemesi gerekmektedir. Özellikle personelin istihdamı ve mesleki gelişimi üzerine sağlıklı kararlar alabilmek için denetim sürecinin daha fazla standartlaştırılması öngörülmektedir (Darling-Hammond, 
Wise ve Pease, 1983). Türkiye'de MEB, denetimde standartlaşmayı sağlamak ve denetçiler arasındaki uygulama birliğini oluşturmak üzere 2016 yılında 16 farklı kurumda kullanılmak üzere denetim rehberlilerini yayımlamıştır. Bu kapsamda Türkiye'de denetime ilişkin bir dönüşüm sürecinin yaşandığı söylenebilir. Bu belge aracılığıyla MEB'in denetim alanına giren birimlere rehberlik etmeyi, faaliyetlerinin mevzuata uygunluğunu analiz etmeyi ve kanıta dayalı biçimde değerlendirme yapmayı hedeflediği görülmektedir (MEB, 2016). Alanyazında okul öncesi eğitim kurumları için geliştirilen denetim rehberinin incelendiği görülmektedir (Turan, 2016). Söz konusu çalışma kapsamında rehberin örnek uygulamaları raporlaması alanyazın ile tutarlı bulunmuştur. Bunun yanında rehberlerin oluşturulmasında akademisyenlerin de görev alması gerektiği önerilmiştir.

\section{Motorlu Taşıt Sürücüleri Kursu Denetim Rehberi}

Motorlu taşıt sürücüleri kursu, karayollarında seyreden araçların güvenli biçimde kullanımı için sürücü adaylarının eğitimlerini sağlamak ve sınavlar sonucunda başarılı olanlara sertifikalarını düzenleme üzere 2918 sayılı Karayolları Trafik Kanununun 123. maddesi gereğince açılmaktadır (Resmi Gazete, 1983). 1920'lerden 1987 yılına kadar bu gereksinim farklı yollarla karşılanmış, ancak 1987 'de Türkiye Büyük Millet Meclisi tarafından onaylanan yasaya göre sürücü belgelerinin özel sürücü kursları tarafından verilmesine karar verilmiştir. Bunun öncesinde trafik tescil müdürlüklerinde başvuruya esas olarak ehliyet verilmekteydi. Motorlu taşıt sürücüleri kursunun açılma izinleri illerin ve ilçelerin nüfus büyüklükleri dikkate alınarak MEB tarafından onaylanmaktadır (Resmi Gazete, 2012).

Türkiye'de 2018 yılı itibariyle toplam 22 milyon 865 bin motorlu araç trafikte yer almaktadır. Yaklaşık 28 milyon 182 bin sürücünün içerisinden erkeklerin oranı \%74,9'dur. Türkiye'de 2018 yılında 418 bin kaza sayısı rapor edilmiştir (Emniyet Genel Müdürlüğü Trafik Başkanlığı, 2018). Trafik kazalarından kaynaklanan yaralanmaların \%50 oranında azaltılması için Birleşmiş Milletler Kalkınma Programının belirlediği ve ülkelerin gerçekleşmesini taahhüt ettiği sürdürülebilir kalkınma hedefi 3.6 doğrultusunda yürütülen çalışmalar karayolu güvenliğinde ciddi ilerlemeleri beraberinde getirmiştir (Jagnoor, Sharma, Parveen, Cox ve Kallakuri, 2020). Bunun yanında motorlu taşıt sürücüleri kursu Trafik Kanunun 8. maddesine göre denetime tabidir. Buna göre, "özel motorlu taşıt sürücüleri kursları her yıl en az bir defa Bakanlık maarif müfettişleri/Bakanlık maarif müfettiş yardımcıları/ müdür yardımcısı/şube müdürleri veya il millî eğitim müdürlüğünce görevlendirilen başka personel tarafından denetime tabi tutulur." Milli Eğitim Bakanlığı motorlu taşıt sürücüleri kurslarının denetimi için 2016 yılında bir rehber yayımlamıştır. Bu kapsamda çalışmanın amacı, motorlu taşıtlar sürücü kursu denetim rehberinin temel bölümlerinin ilgili alan yazın ve yasal mevzuata göre tutarlılığının incelenmesidir. Bu amaç doğrultusunda iki probleme yanıt aranmıştır: (1) Denetim rehberi ile diğer yasal mevzuat arasındaki tutarlılık nasıldır? (2) Denetim rehberi ile alanyazın arasındaki tutarlıık nasıldır? 


\section{YÖNTEM}

Bu bölümde sırasıyla araştırmanın modeline, veri kaynağına ve verilerin analizine yer verilmiştir.

\section{Araştırmanın Modeli}

Bu çalışmada, nitel araştırma yaklaşımı benimsenmiş olup doküman analizi tekniği kullanılmıştır. Bu teknik, araştırma problemiyle yakından ilişkili olan basılı ya da elektronik materyallerin sistematik biçimde incelenmesini hedeflemektedir (Bowen, 2009; Yıldırım ve Şimşek, 2011). Nitel araştırmaların doğası gereği doküman analizinde anlam çıkarmak, anlayış kazanmak ve deneysel bilgi geliştirmek için verilerin incelenmesi ve yorumlanması gerekmektedir (Corbin ve Strauss, 2008). Doküman inceleme, gözlem yoluyla edinilemeyen verilerin toplanmasına olanak sağlamaktadır.

\section{Araştırmanın Verileri}

MEB, okul, kurum ve birimlerin denetiminde maarif müfettişleri başkanlıkları arasındaki uygulama birliğini ve standartlaşmayı sağlamak üzere 16 farklı denetim rehberi yayımlamıştır. Mevcut çalışmada, Motorlu Taşıtlar Sürüsü Kurslarının denetimi için kullanılan rehberlik ve denetim rehberi ele alınmıştır. Bu rehberin birinci bölümünde amaç, kapsam ve dayanak başlığı yer almaktadır. Ardından, sırasıyla rehberlik ve denetimin ilkeleri, esasları ve son bölümde raporlama standartları belirtilmiştir. Raporlama standartları için ilk olarak giriş bölümü ardından eğitim öğretim faaliyetleri, yönetim faaliyetleri, mali iş ve işlemler, izleme ve değerlendirme, yönetici bilgileri, örnek uygulamalar ve genel değerlendirme olmak üzere sekiz alt başıı ve bu alt başlıklar altında 100 madde yer almıştır (MEB, 2016).

\section{Verilerin İşlenmesi ve Analizi:}

Araştırmanın verileri doküman analizi tekniğine uygun olarak çözümlenmiştir. Doküman analizi, araştırılması hedeflenen olgular hakkında bilgi içeren yazılı materyallerin analizini kapsamaktadır (Yıldırım ve Şimşek, 2011). Bu doğrultuda, öncelikle araştırmada kullanılan Motorlu Taşıtlar Sürüsü Kursları Rehberlik ve Denetim Rehberinde yer alan 100 madde, başlık numaralarıyla birlikte ve her biri bir satıra gelecek şekilde Microsoft Excel programına aktarılmıştır. Bunun yanında, belge içerisinde kodların geçtiği bölümler sembollerle gösterilmiştir. Örneğin, "Yasal belgeye ulaşabilme" kodunun yer aldığı D bölümündeki 2.1.1.1 numaralı başıık "D/2.1.1.1" olarak ifade edilmiştir. Bunun yanında denetim rehberinde gönderme yapılan yasal dayaklara İnternet ortamında (http://www.meb.gov.tr/mevzuat) ulaşılmış ve her bir maddenin yanına eklenmiştir. Denetim rehberinde bulunan maddelerin alanyazın ile karşılaştırılması için ise üçüncü bir sütün kullanılmıştır. Verilerin işlendiği tablonun son sütunda ise maddelerin yasal dayanak ile denetim alanyazının karşılaştırılması yapılmıştır. Ayrıca, alanyazın ile karşılaştırma yapmak üzere denetim alanındaki çalışmalar incelenmiştir (Aydın, 2005; Başar, 2000; Robbins vd., 2013). Bu karşılaştırma için kodlar kullanılmış ve kodların birleşimi ile kategoriler oluşturulmuştur. Son olarak kod ve kategoriler yasal dayanak ve alanyazın olmak üzere iki tema altından sınıflandırılmıştır. Çalışma kapsamında 
kullanılan kodların belirlenmesi için diğer okul/kurumlara ait rehberlik ve denetim rehberlerini inceleyen araştırmacılarla ortak bir çerçeve belirlenmiştir. Bununla birlikte uygulama sürecinde kodlara ekleme yapılmıştır (Saldaña, 2009). Tablo 1'de bu araştırma kapsamında verilerin işlenmesi ile birlikte kod, kategori ve temalara örnekler verilmiştir.

Tablo 1'e göre, araştırmacılar öncelikle denetim rehberinde yer alan her bir madde için yasal belge ve alanyazına dayalı olarak kodları atamıştır. Bu uygulamaya örnek vermek gerekirse, denetim rehberinin $D$ bölümünün 2.2.3.1 numaralı başlığında belirtilen "Kurslarda günde 2 saatten az 6 saatten fazla teorik ders yapılmaması" şeklindeki ifade için MTSKY'nin 16/4. Maddesindeki karşılığı incelenmiştir. Bu karşılaştırma sonucunda denetim rehberinin ve yasal belgenin aynı bilgileri içerdiği anlaşılmıştır. Bu doğrultuda "Yasal belge ile birebir örtüşme" kodu kullanılmıştır. Ardından bu kod "Yasal dayanak ile tutarlılık" kategorisi altında gruplanmıştır. Benzer biçimde denetim rehberinin $D$ bölümünün 2.1.3.2 başlığında vurgulanan sürücü adayı sınav aracını belirten yazının kullanılma durumu için MTSKY'nin 17/2-ç maddesi incelenmiştir. Karşılaştırma sonucunda yasal belgenin "Sürücü Adayı Eğitim Aracı" ve "Sürücü Adayı Sınav Aracı" biçiminde güncellendiği ve bu durumun denetim rehberine yansıtılmadığı anlaşılmıştır. Bu doğrultuda "Yasal belgeye göre güncel olmama" kodu kullanılmıştır. Ardından bu kod "Denetim rehberinin yasal belgelerle tutarsızlığı" kategorisi altında sınıflandırılmıştır. İki örnekte belirtilen kategoriler ise "Denetim Rehberinin Yasal Belgelerle Illişkisi" teması altında toplanmıştır.

$\mathrm{Bu}$ araştırmada verilerin işlenmesi ve analizi sürecinde geçerliği ve güvenirliği artırmak amacıyla bazı yöntemlerden faydalanılmıştır. Araştırmanın iç geçerliğini artırmak üzere uzman incelemesine başvurulmuştur (Yıldııım ve Şimşek, 2011). Bu kapsamda, nitel araştırma ve eğitim denetimi konusunda uzman iki akademisyenden yardım alınmıştır. Ayrıca, diğer denetim rehberlerini inceleyen araştırmacılarla üç ay boyunca Internet ortamında her hafta toplantılar yapılmıştır. Bu toplantılarda tema, kategori ve kodların belirlenmesi ve verilerin analizi süreçlerine ilişkin görüş alış verişinde bulunulmuştur. Araştırmanın dış geçerliliğini artırmak amacıyla ayrıntılı betimleme yönteminden faydalanılmıştır (Yıldırım ve Şimşek, 2011). Bu kapsamda, bulgular kısmında yeri geldikçe denetim rehberinde yer alan maddeler doğrudan aktarılmıştır. Bu sayede okuyucunun ham veriyi görmesi hedeflenmiştir. Öte yandan, mevcut çalışmanın iç güvenirliğini artırma amacıyla veriler "önceden oluşturulmuş ve ayrıntılı olarak tanımlanmış bir çerçeveye bağlı olarak" analiz edilmiştir (Yıldırım ve Şimşek, 2011). Bunun için analiz öncesinde diğer denetim rehberleri üzerinde çalışma yapan araştırmacılarla kod, kategori ve temalara ilişkin ortak bir çerçeve belirlenmiştir. Mevcut araştırmanın verileri bu çerçeveden yola çıkılarak analiz edilmiştir. Ayrıca, araştırmanın iç güvenirliğine katkı sunması açısından farklı bir araştırmacıdan yardım istenmiş ve bir bölümün verilerinin çözümlenmesi ve kodlamalarının yapılması istenmiştir. Ardından araştırmacılar elde ettiği bulgular arasında karşılaştırma yapmış ve aralarında uyum olduğu görülmüştür. Araştırmanın dış güvenirliğini artırma amacıyla veri toplama ve analiz sürecine ilişkin ayrıntılı açıklamalara yer vermeye çalışılmıştır (Yıldırım ve Şimşek, 2011). Bu doğrultuda verilerin analiz yapılacak programa nasıl aktarıldığı, kodlama yönetiminin nasıl gerçekleştiği ve kodlardan kategorilere/temalara nasıl ulaşıldığı detaylı biçimde açıklanmaya çalışılmıştır. 
Tablo 1. Denetim rehberi ile yasal mevzuat ve alanyazının karşılaştırma süreci

\begin{tabular}{|c|c|c|c|c|c|c|}
\hline \multicolumn{2}{|c|}{ Denetim Rehberindeki Maddenin } & \multirow{2}{*}{ Yasal Belge/Alanyazın Karşılığı } & \multirow{2}{*}{ Analiz } & \multirow{2}{*}{ Kod } & \multirow{2}{*}{ Kategori } & \multirow{2}{*}{ Tema } \\
\hline No'su & İçeriği & & & & & \\
\hline 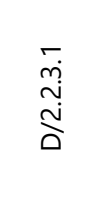 & $\begin{array}{l}\text { Kurslarda günde } 2 \text { saatten az } 6 \text { saatten } \\
\text { fazla teorik ders yapılmaması; } \\
\text { Direksiyon eğitimi derslerinin her bir } \\
\text { kursiyer için ayrı ayrı olmak üzere } \\
\text { günde } 2 \text { saatten fazla yapılmaması. }\end{array}$ & $\begin{array}{l}\text { Kurslarda günde } 2 \text { saatten az } 6 \text { saatten fazla } \\
\text { teorik ders yapılamaz. Direksiyon eğitimi } \\
\text { dersleri her bir kursiyer için ayrı ayrı olmak } \\
\text { üzere günde } 2 \text { saatten fazla yapılamaz } \\
\text { (MTSKY, Md. 16/4). }\end{array}$ & $\begin{array}{l}\text { Denetim rehberindeki madde ile } \\
\text { MTSKY'nin 16/4. maddesi birebir } \\
\text { örtüşmektedir. }\end{array}$ & $\begin{array}{l}\text { Yasal belge ile } \\
\text { birebir örtüşme }\end{array}$ & $\begin{array}{l}\text { Denetim } \\
\text { rehberinin yasal } \\
\text { belgelerle } \\
\text { tutarlıı̆ı̆ı }\end{array}$ & \multirow{2}{*}{ 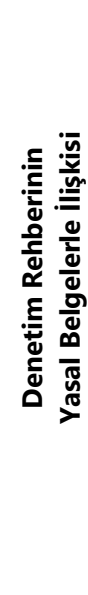 } \\
\hline$\underset{\stackrel{\sim}{m}}{\stackrel{\grave{\Sigma}}{\grave{a}}}$ & $\begin{array}{l}\text { Üst kısmına mavi zemin üstüne beyaz } \\
\text { yazı ile ön ve arkasında sadece "Sürücü } \\
\text { Adayı" ifadesi bulunan ve görülebilir } \\
\text { net alanı } 15 \times 60 \text { ebadındaki fosforlu } \\
\text { veya ışıklı levha konulması }\end{array}$ & $\begin{array}{l}\text { (Değişik:RG-7/3/2017-30000) Direksiyon } \\
\text { eğitim ve sınav aracının üst kısmına, mavi } \\
\text { zemin üstüne beyaz yazı ile ön ve arkasında } \\
\text { eğitim esnasında sadece "Sürücü Adayı } \\
\text { Eğitim Aracı" sınav esnasında ise sadece } \\
\text { "Sürücü Adayı Sınav Aracı" ifadesi bulunan ve } \\
\text { görülebilir net alanının yüksekliği } 15 \mathrm{~cm} \text {, eni } \\
60 \mathrm{~cm} \text { ebadında fosforlu veya ışıkı levha } \\
\text { konulur (MTSKY, Md.17/2-ç). }\end{array}$ & $\begin{array}{l}\text { Denetim rehberindeki madde sadece } \\
\text { "Sürücü Adayı" aracını vurgulamaktadır. } \\
\text { Buna karşın, MTSKY'nin 17/2-ç maddesi } \\
2017 \text { yıında güncellenmiş ve bu araçları } \\
\text { "Sürücü Adayı Eğitim Aracı" ve "Sınav } \\
\text { Aracı" olarak iki ayırmıştır. Bu güncelleme } \\
\text { denetim rehberine yansımamıştır. }\end{array}$ & $\begin{array}{l}\text { Yasal belgeye } \\
\text { göre güncel } \\
\text { olmama }\end{array}$ & $\begin{array}{l}\text { Denetim } \\
\text { rehberinin yasal } \\
\text { belgelerle } \\
\text { tutarsızlığı }\end{array}$ & \\
\hline$\stackrel{\stackrel{v}{\mathrm{U}}}{\mathrm{U}}$ & $\begin{array}{l}\text { Denetim grubu, rehberlik ve denetim } \\
\text { uygulaması öncesinde denetlenecek } \\
\text { kurum/okul yönetimiyle rehberlik ve } \\
\text { denetimin amacı, süresi ve kapsamılyla } \\
\text { ilgili bir toplantı gerçekleştirir. }\end{array}$ & $\begin{array}{l}\text { Çağdaş denetimde denetlenecek olan kişiye } \\
\text { önceden haber verilir ve bir ön görüşme } \\
\text { yapılır (Başar, 2000). }\end{array}$ & $\begin{array}{l}\text { Denetim rehberinde denetimden önce bir } \\
\text { toplantı yapılması gerektiği } \\
\text { belirtilmektedir. Benzer şekilde alanyazında } \\
\text { çağdaş denetimin önceden haber verilerek } \\
\text { yapılıması gerektiği belirtilmektedir. }\end{array}$ & $\begin{array}{l}\text { Denetim } \\
\text { öncesinde haber } \\
\text { verme }\end{array}$ & $\begin{array}{l}\text { Denetim } \\
\text { rehberinin } \\
\text { alanyazınla } \\
\text { tutarlıı̆ı̆ı }\end{array}$ & \multirow{2}{*}{ 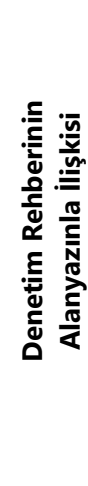 } \\
\hline$\frac{\stackrel{n}{i}}{\stackrel{n}{i}}$ & $\begin{array}{l}\text { Kurumda düzen ve temizliğinin } \\
\text { sağlanmış olması (MEB 2009/20 Sayılı } \\
\text { Genelge) }\end{array}$ & $\begin{array}{l}\text { Değerlendirme ölçüm sonuçlarının bir ölçüte } \\
\text { göre karşılaştırılması ile yapııır (Başar, 2000). }\end{array}$ & $\begin{array}{l}\text { Denetim rehberinde değerlendirme ölçütü } \\
\text { açıç̧a belirtilmemiştir. Düzen ve temizliğin } \\
\text { sağlanma durumu kişiden kişiye farklılık } \\
\text { gösterir. Buna karşın alanyazında } \\
\text { değerlendirmenin yapılabilmesi için } \\
\text { ölçütlerin belli olması gerektiği } \\
\text { vurgulanmaktadır. }\end{array}$ & $\begin{array}{l}\text { Değerlendirme } \\
\text { ölçütünün } \\
\text { olmaması }\end{array}$ & $\begin{array}{l}\text { Denetim } \\
\text { rehberinin } \\
\text { alanyazınla } \\
\text { tutarsızlığı }\end{array}$ & \\
\hline
\end{tabular}





\section{BULGULAR}

Bu alt bölümde, yasal mevzuat ve alanyazın temelinde incelenen denetim rehberinden elde edilen bulgular iki tema altında sunulmuştur. Birinci başıkta, denetim rehberi ile yasal mevzuat arasındaki tutarlılık karşılaştırılmıştır. İkinci başlıkta ise denetim rehberi ile alanyazın arasındaki tutarlılık ele alınmıştır.

\section{Tema 1: Denetim Rehberinin Yasal Belgelerle iliş̧kisi}

Araştırmanın birinci alt problemi, denetim rehberi ile yasal belgeler arasındaki tutarlıı̆ıın karşılaştııımasına dönüktür. Denetim rehberi ile yasal mevzuat arasındaki tutarlıı̆ın karşılaştırılması için yapılan içerik analizi sonucunda dokuz koda ve iki kategoriye ulaşılmıştır. Bu kapsamda, yasal mevzuat temelinde incelenen denetim rehberine ait sonuçlar Tablo 2' de yer almaktadır.

Tablo 2. Denetim rehberi ile yasal belgeler arasındaki tutarlıı̆ın karşılaştırılması

\begin{tabular}{|c|c|c|c|}
\hline Kategori & Kod & Denetim Rehberindeki Örnek & Sıklık \\
\hline \multirow{3}{*}{$\begin{array}{l}\text { Denetim rehberinin } \\
\text { yasal belgelerle } \\
\text { tutarlılığı }\end{array}$} & Yasal belgeye ulaşabilme & $\mathrm{D} / 2.1 .1 .1 ; \mathrm{D} / 2.1 .3 .2 ; \mathrm{D} / 2.3 .2 .1$ & 87 \\
\hline & Yasal belge ile birebir örtüşme & $\begin{array}{l}\mathrm{D} / 2.1 .1 .2 ; \mathrm{D} / 2.1 .1 .4 ; \mathrm{D} / 2.1 .2 .1 \\
\mathrm{D} / 2.1 .3 .2 ; \mathrm{D} / 2.1 .3 .2 ; \mathrm{D} / 2.1 .3 .2\end{array}$ & 36 \\
\hline & Toplam & & 123 \\
\hline \multirow{8}{*}{$\begin{array}{l}\text { Denetim rehberinin } \\
\text { yasal belgelerle } \\
\text { tutarsızlığı }\end{array}$} & Madde numaralarındaki tutarsızlık & $\mathrm{D} / 2.1 .1 .1 ; \mathrm{D} / 4.1 .3$ & 2 \\
\hline & Yasal belgeyi uygun ifade etmeme & $\mathrm{D} / 2.1 .3$ & 3 \\
\hline & Yasal belgeye göre güncel olmama & $\begin{array}{l}\mathrm{D} / 2.1 .3 ; \mathrm{D} / 2.1 .1 .4 ; \mathrm{D} / 2.2 .2 ; \\
\mathrm{D} / 2.2 .3 ; \mathrm{D} / 3.3 ; \mathrm{D} / 4.1 .1 ;\end{array}$ & 9 \\
\hline & Yasal belgenin yürürlükten kaldırılması & $\mathrm{D} / 2.1 .2 .3$ & 1 \\
\hline & Denetim rehberinin daha az bilgi içermesi & $\begin{array}{l}D / 2.1 .1 .4 ; D / 2.1 .2 .2 ; D / 2.1 .2 .3 ; \\
D / 2.2 .3 ; D / 3.2 ; D / 3.4 ; D / 3.5\end{array}$ & 29 \\
\hline & Yasal belgeye gönderme yapmama & $\begin{array}{l}\text { A (Dayanak); D/3.7; D/3.9; } \\
\text { D/3.11 }\end{array}$ & 5 \\
\hline & Yasal belge belirsizliği & A (Tanımlar); D/2.2.3 & 2 \\
\hline & Toplam & & 51 \\
\hline
\end{tabular}

Açıklama: Denetim rehberindeki örneğin verildiği sütunda örneğin içeriği yerine başlık numarası verilmiştir.

Tablo 2 incelendiğinde, yasal dayanak ile tutarlı olma durumu belgeye ulaşılıp ulaşılmadığını ve yasal belge ile örtüşme durumunu ifade etmektedir. Rehberin çoğunluğunda gönderme yapılan yasal belgeye ulaşıldığı ve rehberdeki ifade ile yasal dayanağın örtüştüğü görülmektedir. Bu kapsamda belgenin önemli bir bölümünün yasal dayanak ile tutarlı olduğu söylenebilir. Bunun yanında bazı maddelerde yasal dayanağa göre eksik ifade edilmiş bilgiler bulunmaktadır. Örneğin, D bölümü 2.1.3 alt başlığında yer alan madde "kursların direksiyon eğitim alanı ve dinlenme tesisi ile direksiyon eğitim simülatörünün, Genel Müdürlükçe belirlenen standartlara uygun şekilde düzenlenmesi" biçimindedir. Bu madde içerisinde yer alan standartların neler olduğu ise ÖÖKSY (Özel Eğitim Kurumları Standartları Yönergesi) incelenerek anlaşılmaktadır. Bu kapsamda, denetçinin rehber ile birlikte yönergedeki bilgileri de 
incelemesi gerekmektedir. Bu haliyle rehberin tek başına yeterli olmadığı ve yönergeye göre daha az bilgi içerdiği söylenebilir.

Yine Tablo 2'ye göre, denetim rehberinin yayımlanmasından sonra yönetmeliklerin bazı maddelerinde değişiklikler yapıldığı halde bu değişikliklerin belgeye yansımadığı anlaşıımaktadır. Örneğin, D bölümü 2.1.3 alt başlığında adayın eğitim ve sınav için kullanacağı araçlar için yaş sınırlamasında değişikliğe gidilmiştir. Buna göre, 2017 yılında MTSKY (Millî Eğitim Bakanlığı Özel Motorlu Taşıt Sürücüleri Kursu Yönetmeliği) içerisinde 17/2-d maddesinde değişiklik yapılmış ve araçların kullanılabilme sınırı iki yaş yükseltilmiştir. Bu durum denetim rehberinde 2016 yılı öncesindeki hali ile kalmıştır. Ayrıca, kurum temizliği başlığı altında MEB'in 2009 yılında yayımladığı 20 sayılı genelgeye gönderme yapılmasına karşın bu genelgenin yürürlükten kaldırılmış olduğu anlaşılmaktadır. Her iki durum ele alındığında yasal belge içeriğinde yapılan değişikliklerin denetim rehberine yansımamış olduğu söylenebilir.

Bunun yanında, rehberde yer alan bir diğer durum ise gönderme yapılan yasal dayanağın uygun ifade edilmemiş olduğudur. Örneğin, D bölümü 2.1.3 alt başlığında yer alan ÖÖKSY kısaltmasına ait yasal mevzuat belge içerisinde ilk geçtiği yerde açıça yazılmamış ve kısaltmalar bölümünde yer verilmemiştir. Ayrıca, bazı maddelerin atıf bilgileri ile yasal belge numarasının örtüşmediği görülmektedir. Örneğin, "Bina da Türk Bayrağı ve Atatürk Köşesi ile ilgili düzenlemelerin yeterlik durumu" için ÖÖKSY'nin 32. maddesine gönderme yapılmıştır (D/2.1.1.1). Buna karşın ilgili yönergenin 32. maddesi Sosyal Etkinlik Merkezlerine yönelik düzenlemeleri içermektedir. Özel Motorlu Taşıt Sürücüleri Kursları ise yönergenin 35. maddesinde yer almaktadır. Bu kapsamda bazı maddeler için yasal dayanağın hatalı ifade edildiği söylenebilir.

Rehberde yer alan bir diğer husus ise yasal dayanak belirsizliği temasında gerçekleşmektedir. Bu kapsamda rehber içerisinde yer alan bazı maddeler için yasal dayanağa açıkça gönderme yapılmadığı görülmektedir. Söz konusu maddelerin biri yönetim faaliyetleri içerisinde bulunan reklam ve ilanların arşivlenmesiyle ilgilidir ( $D / 3.7)$. Rehberde bu maddenin yasal dayanağına yer verilmemiştir. Ayrıca tanımlar kısmında yer alan kavramların yasal belgeler içerindeki tanımlamalarından farklı olduğu görülmektedir.

\section{Tema 2: Denetim Rehberinin Alanyazınla iliş̧kisi}

Denetim rehberi ile alanyazın arasındaki tutarlıı̆̆ın karşılaştırılması için yapılan içerik analizi sonucunda on beş koda ve altı kategoriye ulaşılmıştır. Bu kapsamda alanyazın temelinde incelenen denetim rehberine ait sonuçlar Tablo 3'de yer almaktadır.

Tablo 3. Denetim Rehberi ile Alanyazın Arasındaki Tutarlıı̆ın Karşılaştırılması

\begin{tabular}{|c|c|c|}
\hline Kategori & Kod & Denetim Rehberindeki Örnek \\
\hline \multirow{3}{*}{$\begin{array}{l}\text { Denetim rehberinin } \\
\text { alınyazınla tutarlılığı }\end{array}$} & Değerlendirme ölçütünün rehberde olması & $\begin{array}{l}\mathrm{D} / 2.1 .1 .1 ; \mathrm{D} / 2.1 .1 .2 ; \mathrm{D} / 2.1 .1 .4 ; \\
\mathrm{D} / 2.1 .2 .1 ; \mathrm{D} / 2.1 .3 .2\end{array}$ \\
\hline & Karara katılım & $\mathrm{C} / 2.4$ \\
\hline & Denetim öncesinde haber verme & $\mathrm{C} / 2.4$ \\
\hline \multirow{4}{*}{$\begin{array}{l}\text { Denetim rehberinin } \\
\text { alanyazınla } \\
\text { tutarsızlığı }\end{array}$} & Değerlendirme ölçütünün rehberde olmaması & $\begin{array}{l}D / 2.1 .2 .2 ; D / 2.1 .2 .3 ; D / 2.1 .3 .2 ; \\
D / 3.11 ; D / 3.9\end{array}$ \\
\hline & Birbirine çok yakın (binişik) maddeler & $D / 3.2 ; D / 4.1 .3$ \\
\hline & Atıfsızlık & B (Rehberlik ve Denetim Illkeleri) \\
\hline & İçerik eksikliği & B (Rehberlik ve Denetim İlkeleri) \\
\hline
\end{tabular}

Açıklama: Denetim rehberindeki örneğin verildiği sütunda örneğin içeriği yerine başlık numarası verilmiştir. 
Tablo 3 incelendiğinde, rehberin bazı yönlerinin alanyazın ile tutarlı olduğu görülmektedir. Bu kapsamda, rehber içerisinde yer alan bazı maddelerde denetçinin karar vermesine yardımcı olacak değerlendirme ölçütlerinin bulunduğu anlaşılmaktadır. Örneğin, direksiyon eğitim araçları başlığı altında eğitim ve sınav aracı olarak kullanılanların sağ ve sol yanlarına (en az 400 punto) olacak şekilde kursun adı ve telefonunun yazılması gerektiği vurgulanmaktadır. Buradaki ölçüt yazıların en az 400 punto olacak şekilde belirlenmiştir (D/2.1.3.2). Ayrıca, denetim sonrasında hazırlanan sonuçların ve önerilerin kurum personeli ile paylaşılarak değerlendirilmesi hedeflenmiştir (C/2.4). Bu kapsamda denetimde paydaşların karara katılımının gözetildiği söylenebilir. Bunun yanında, denetime gitmeden önce kurum yönetimiyle rehberlik ve denetimin amacı, süresi ve kapsamıla ilgili bir toplantı gerçekleştirilmektedir (C/2.4). Bu sayede denetimin planlı bir iş olduğu ve önceden haber verilerek gerçekleştiği söylenebilir.

Öte yandan, denetim rehberinde alanyazın ile aykırı olan durumlar bulunmaktadır. Bunlardan birinde denetim rehberinde bazı maddeler için değerlendirme ölçütlerinin yer almadığı anlaşılmaktadır. Örneğin, D bölümünde yer alan 2.1.2.2 başlığında "yangın dolabının oluşturulması" ölçülen bir özellik olmasına karşın bunun değerlendirilmesinde hangi ölçütün ele alınacağı belli değildir. İlgili yönetmelikte ise bu dolabın içeriğinin nelerden oluşacağı gibi detaylı ölçütler vardır. Benzer biçimde, "kurumda düzen ve temizliğinin sağlanmış olması" maddesinde değerlendirmenin hangi ölçüte göre yapılacağı belirsizdir (D/2.1.2.3). Bu kapsamda, denetim rehberinde yer alan bazı ölçütlerin belirsiz olduğu görülmekte ve yönetmeliğe ulaşılarak detaylı bilgilerin elde edilmesi gerekmektedir. Bu durum denetim sürecinde birden fazla belgenin eş zamanlı biçimde kontrol edilmesi anlamına gelmektedir.

Bunun yanında, Tablo 3'e göre rehberde birbirine çok yakın ve tekrara kaçan maddeler yer almaktadır. Örneğin, D bölümde 4.1 .3 başlığında çalışma izinlerinin valilikten alınması ve ek ders ücretin onay alındıktan sonra ödenmeye başlanması gerektiği belirtilmektedir. Benzer biçimde $D$ bölümünün 3.2 başığında atama ve görevlendirme için valilikten izin alınması gerektiği vurgulanmaktadır. Bu iki maddenin birbirine yakın olduğu ve istenilen özelliği birden çok madde ile ölçüldüğü söylenebilir. Tablo 3'te kod olarak kullanılan "atıfsızlık" kavramı, rehber içerisinde ilgili alanyazına gönderme yapılmadığı anlamı taşımaktadır. Bu kapsamda rehberde yer alan ifadelerin geçmiş bilimsel çalışmalara gönderme yapılmadan kullanıldığı görülmektedir. Bu durum rehberin sadece mevzuat odaklı hazırlandığı izlenimini yansıtmaktadır. Denetim rehberinde yer alan bir diğer husus alanyazına göre içerik eksikliğinde yaşanmıştır. Bu kapsamda, öz değerlendirme ve hesapverebilirlik gibi çağdaş denetim ilkelerinin rehberde yer almadığı görülmektedir.

\section{TARTIŞMA}

$\mathrm{Bu}$ araştırma ile motorlu taşıtlar sürücü kursu denetim rehberinin temel bölümlerinin ilgili alanyazın ve yasal mevzuata göre tutarlıı̆̆ı incelenmiştir. Bu doğrultuda Milli Eğitim Bakanlığının maarif müfettişleri başkanlıkları arasındaki uygulama birliğini ve standartlaşmayı sağlamak üzere yayımlamış olduğu denetim rehberleri içerisinden motorlu taşıtlar sürücü kursları için hazırlanan doküman 
değerlendirilmiştir. Araştırma kapsamında elde edilen bulguya göre, motorlu taşıt sürücüleri kurslarına yönelik hazırlanan denetim rehberinin çoğunluğunda gönderme yapılan yasal belgeye ulaşıldığı ve rehberdeki ifade ile yasal dayanağın örtüştüğü görülmüştür. Bu yönü ile rehberin, ilgili yasal belgeler açısından denetim sürecine yol gösterici ve düzeltme-geliştirme odaklı olduğu söylenebilir. Bu durum çağdaş denetim anlayışını yansıtan alanyazın ile uyumludur (Başar, 2000). Buna karşın mevcut araştırmada bazı maddelerin yasal dayanağa göre eksik ifade edilmiş olduğu saptanmıştır. Araştırma kapsamında elde edilen bu Toprakçı ve Bakır (2019) tarafından yürütülen çalışmanın sonuçlarıyla tutarlıık göstermektedir. Söz konusu araştırmada 10. Kalkınma Planı, 2018 Yılı Programı ve MEB 2015-2019 Stratejik Planı arasında bazı konularda uyumun olmadığı görülmüştür. Denetim rehberi ile yasal mevzuat arasındaki durum hem denetçinin hem de denetlenenin rehber ile birlikte yasal belgeye bakmasını zorunlu hale getirmektedir. Birden fazla belgenin kullanılması uygulayıcılar açısından sorun oluşturabilir ve denetimde standartlaşmayı engelleyebilir. Bu kapsamda rehberin bazı yönleri ile kullanıc dostu olmadığı söylenebilir. Bu durumun muhtemel nedenlerinden birisi karayolları trafiği güvenliğinde önemli bir role sahip olan motorlu taşıt sürücüleri kurslarının denetimi ile birlikte yapılmak istenen değişimin bu belgeyi hazırlayanlara tam olarak aktarılamaması olarak gösterilebilir. Nitekim Bass ve Avolio (1993), dönüşümcü liderlerin zihnindeki değişim modelinin takipçilerin zihninde de oluşturması gerektiğini belirtmektedir. Bu bulgudan hareketle değişimi başlatacak olan üst düzey yöneticilerin model oluşturma ve bu modeli astlarına aktarma konusunda eksik kaldıkları söylenebilir.

Araştırma kapsamında elde edilen bir diğer bulgu, yasal belgeler içerisinde bazı maddelerde değişiklikler yapılmasına karşın denetim rehberinin 2016 yılındaki hali ile kullanıldığını göstermiştir. Bu kapsamda, rehberin giriş kısmında vurgulanan güncel olması gerektiği hususu (MEB, 2016) göz ardı edilmiş ve güncellemelerin belgeye yansıtılmadığı anlaşılmıştır. Konu bu açıdan değerlendirildiğinde, MEB birimleri arasında eşgüdümün oluşmadığı ve bir birimde yapılan değişikliklerin onunla ilişkili diğer birimlere yansımadığı söylenebilir. MEB denetim rehberi ile birlikte sürücü kurslarının süreç ve sonuçlarını mevzuata göre analiz etmeyi hedeflemektedir (MEB, 2016). Bu açıdan bakıldığında yasal belgelere göre denetim rehberinde güncel olmayan maddelerin bu hedefe ulaşmada yol gösterici olması zordur. Geçmiş araştırma bulguları denetimin dinamik bir süreç olduğunu ve denetime rehberlik eden belgelerin zaman içerisinde güncellenmesi gerektiğini ortaya koymaktadır (Medori ve Steeple, 2000). Denetim standartlarının belli bir zaman diliminde geçerli olduğu ve bu geçerlilik sürelerinin de rehberlerde ayrıca belirtildiği görülmektedir (Archambeault Deborah, 2014).

Çalışmanın bir diğer sonucuna göre, motorlu taşıt sürücüleri kursunun denetim rehberinin bazı yönlerinin alanyazın ile tutarlı olduğu görülmüştür. Rehberde birçok madde içerisinde değerlendirme ölçütleri bulunmaktadır. Bu sayede denetçi ölçüm sonucunu bir ölçüte göre karşılaştırıp değerlendirme yapabilir. Ayrıca, rehberde denetim öncesinde kurum çalışanları ile ön görüşme yapılması gerektiği belirtilmektedir. Kuruma denetim öncesinde haber verilmesi kişilerde özdenetim yoluyla eksik ve yanlışlarından kurtulma olanağı sunmaktadır (Aydın, 2005). MEB, yapılacak gözlem ve incelemenin haber verilmesiyle birlikte kişilerde özdenetimin oluşmasına katkı sunduğu söylenebilir. Yine rehberde denetim sonrasında toplantı yapılması hedeflenmiştir. Çağdaş denetim, örgüt çalışanlarının kararlara katılımını öngörür. 
Gözlem sonrası görüşme bilgi kaybını önlemesi bakımından önemlidir. Alanyazında okul öncesi eğitim kurumları için hazırlanan denetim rehberinin incelediği çalışmada ise rehberin denetim önerilerini içermesinin alanyazın ile tutarlı olduğunu belirtmiştir (Turan, 2016). Bunun yanında karara katılım olanağı sunulduğu anlaşılmaktadır.

Diğer taraftan, denetim rehberinde yer alan bazı maddelerin değerlendirme ölçütlerinin olmadığı anlaşılmıştır. Bir değerlendirmeye varabilmek için ölçüm yapılan özelliğin bir ölçüte göre karşılaştııılması gerekmektedir (Başar, 2000). Bu kapsamda denetim rehberinde yer alan bazı maddelerin muğlak ifade edilmesinden dolayı deneticinin nesnel değerlendirme yapmasının güç olabileceği söylenebilir. Nitekim Beytekin ve Tas (2017) ortaokul müdürlerinin görüşlerini incelediği çalışmalarında denetimin geliştirilmesi için denetimde kullanılan ölçütlerin nesnel olması gerektiği sonucuna ulaşmışlardır. Benzer biçimde Köybaşı, Uğulu, Ağıroplu Bakır ve Karakuş (2017) Sivas ilinde öğretmenlerin görüşlerine dayalı olarak yapmış olduğu çalışmasında ders denetiminin objektif bir ölçme ve değerlendirme sürecini içermediği sonucuna ulaşmıştır. Denetimde objektif ölçütlerin kullanılması denetçiler arasında uygulama farklııklarına da yol açabilir. Bir denetçinin kurum hakkında gördüğünü diğer bir denetçi göremeyebilir. $\mathrm{Bu}$ durum denetlenen kurumların denetim mekanizmasına güvensizliğine neden olabilir (Robbins vd., 2013). Aynı zamanda denetim ile ölçülen hedeflerin istenilenden ne kadar saptığını tespit etmek güçleşecektir. Nitekim okul öncesi eğitim kurumları denetim rehberini inceleyen Turan (2016) yapmış olduğu çalışmasında denetim raporlarını incelemiş ve denetim rehberinde yer almasına karşın birçok maddede maarif müfettişlerinin değerlendirme yapmadıkları veya yapamadıkları sonucuna ulaşmıştır.

Denetim rehberinin alanyazın ile karşılaştırılması sonucunda ulaşılan bir diğer sonuç ise ölçülmek istenen özelliklerin farklı maddeler içinde tekrardan ele alındığını göstermiştir. Ayrıca mevcut çalışma kapsamında denetim rehberinin alanyazına atıf yapılmadan oluşturulduğu sonucuna ulaşılmıştır. Denetim anlayışındaki değişme ve gelişmelerin denetim rehberine yansıtılırken alanyazın desteği alınması kapsam geçerliliği açısından önemlidir. Öte yandan rehberde öz değerlendirmeye yer verilmediği saptanmıştır. Kurumun öz değerlendirme yapması eğitimde yenilikleri takip etme ve bu yenilikleri bünyesine alma konusunda önemli bir role sahiptir. Kendi eksiğinin farkında olan kurumlar gelişimlerini tamamlamak için daha güçlü çaba sarf edebilirler. Örneğin, Schildkamp, Visscher ve Luyten (2009) Hollanda'daki 79 ilköğretim okulunun öz değerlendirme çalışmalarını beş yıl boyunca incelemiştir. Analiz sonuçları, öz değerlendirme çalışmalarının okulun öğrenci başarısına katkı sunduğunu ortaya koymuştur.

\section{SONUÇ ve ÖNERILER}

Bu bölümünde, öncelikle çalışmanın sınırlılıkları ele alınmış ve ileriki araştırmalar için önerilerde bulunulmuştur. Ardından ulaşılan sonuçlara dayalı olarak uygulayıcılara önerilerde bulunulmuştur. Bu araştırmada motorlu taşıtlar sürücü kursu denetim rehberi incelendiğinden çalışma doküman incelemesiyle sınırılık taşımaktadır. İleriki araştırmalarda, denetçilerin, kurs yöneticilerinin, öğreticilerinin ve sürücü adaylarının denetim rehberi hakkındaki görüş ve deneyimleri içeren bir durum çalışması 
tasarlanabilir (Stake, 1995; Yin, 2003). Bunun yanında, motorlu taşıt sürücüleri kurslarının denetimi sonucunda maarif müfettişlerinin hazırlamış olduğu denetim raporları incelenerek çoklu doküman incelemesi yapılabilir. İlgili alanyazında motorlu taşır sürücü kurslarının denetimine ilişkin az sayıda araştırmaya rastlanılmıştır. Bu çalışma kapsamında sadece nitel veriler analiz edilmiştir. Ileriki araştırmalarında, kursların denetimi ile ilişkili olabilecek (örneğin, personelin mesleki gelişimi ve örgüt iklimi) değişkenlerin ele alındığı ilişkisel tarama modelleri oluşturulabilir.

Karayolu trafik kazalarında genç sürücülerin payının yüksek olması bu sürücülerin yetiştirilmesinde görevli olan motorlu taşıt sürücüleri kurlarında sunulan eğitimin niteliğini ön plana çıkarmaktadır. Bu kursların denetimi kurumsal gelişim açısından son derece önemlidir. Mevcut araştırmanın sonuçları, motorlu taşıt sürücüleri kurslarının denetimi için hazırlanan denetim rehberinin tek başına yeterli olmadığını ve denetim sürecinde diğer yasal belgelere bakma zorunluluğu oluşturduğunu göstermiştir. Denetim rehberi oluştururken kullanışlılık ilkesi göz önüne alınmalı ve yasal mevzuatı tam olarak içerecek şekilde hazırlanması sağlanmalıdır. Denetim rehberini kullanan denetçilerin ve denetlenen kurumların tek bir belge üzerinden hazırlık yapması karışıklığı önleyebilir. Bir diğer sonuca göre, denetim rehberinin güncelleme konusunda yönetmeliğin gerisinde kaldığı görülmüştür. Bu kapsamda Milli Eğitim Bakanlığı yönetmelik üzerinde yapacağı değişiklikleri eş zamanlı biçimde denetim rehberine yansıtılması önerilmektedir. Bunun için denetim rehberinin dijital ortamda dinamik olarak tasarlanması ve gönderme yapılan yönetmeliklerle ilişkilendirilmesi sağlanabilir. Mevcut araştırmanın sonuçları denetim rehberinde yer alan bazı maddelerin muğlak ifade edildiğini ve değerlendirme yapabilmek için bir ölçütün yer almadığını göstermiştir. Ayrıca, denetim rehberindeki bazı maddelerin değerlendirilmesi için gerek duyulan ölçüte yasal belgeler aracılığıyla ulaşıldığı saptanmıştır. Kullanışlılık açısından ve değerlendirmenin objektif biçimde yapılabilmesi için denetim rehberindeki her bir maddenin ölçütlerinin/standartlarının belirtilmesi gerekmektedir. Böylece ölçütler ortaklaşarak değerlendirme farklılıkları azaltılmış olur. Aynı zamanda denetimde nesnellik sağlanmış olacaktır. Mevcut araştırmadan elde edilen bir diğer sonuca göre denetim rehberinde tekrara kaçan maddelerin olduğu anlaşılmıştır. Bu doğrultuda işin değerlendirilmesi için kullanılan ölçütlerinden tekrara kaçan yönler belirlenmeli ve denetim rehberi de düzeltilip geliştirilmelidir. Denetim rehberi oluşturulurken hangi işlem basamaklarının takip edildiği ve ölçme aracının geliştirilmesi aşamalarına uyulup uyulmadığı paylaşılmalıdır. Denetim rehberinin güvenirlik ve geçerlik çalışmaları dikkatle yürütülmelidir. Alanyazında önemi vurgulandığı halde denetim rehberinde yer almayan bir diğer konu ise öz değerlendirme etkinliklerine yer verilememesidir. Kurumsal gelişim açısından öz değerlendirme çalışmalarını teşvik edecek düzenlemeler yapılmalıdır.

\section{KAYNAKLAR}

Archambeault Deborah, S. (2014). Divergent and Evolving Auditing Standards: Teaching Guide and Exercises Advances in Accounting Education: Teaching and Curriculum Innovations (Vol. 14, ss. 73-99): Emerald Group Publishing Limited.

Aydın, M. (2005). Eğitim yönetimi. Ankara: Hatipoğlu.

Bass, B. M. ve Avolio, B. J. (1993). Transformational leadership: A response to critiques. . M. M. Chemers ve R. Ayman (Eds.). Leadership theory and research. New York: Academic.

Başar, H. (2000). Eğitim denetçisi. Ankara: Pegem. 
Beytekin, O. F. ve Tas, Ş. (2017). Ortaokul müdürlerinin öğretimsel denetime ilişkin görüşlerinin incelenmesi. Turkish Studies, 12(33), 115-128.

Bitan, K., Haep, A. ve Steins, G. (2015). School inspections still in dispute-an exploratory study of school principals' perceptions of school inspections. International Journal of Leadership in Education, 18(4), 418-439.

Bowen, G. A. (2009). Document analysis as a qualitative research method. Qualitative research journal, 9(2), 27-40.

Cohen, J. ve Goldhaber, D. (2016). Building a more complete understanding of teacher evaluation using classroom observations. Educational Researcher, 45(6), 378-387.

Corbin, J. ve Strauss, A. (2008). Basics of qualitative research: Techniques and procedures for developing grounded theory (3rd Baskı). Thousand Oaks, CA: Sage.

Darling-Hammond, L., Wise, A. E. ve Pease, S. R. (1983). Teacher evaluation in the organizational context: A review of the literature. Review of Educational Research, 53(3), 285-328.

Doğru, G. (2018). Motorlu taşıtlar sürücü kursiyerleri teorik sınavı ile elektronik sınavının çeşitli değişkenler açısından karşılaştırılması. Yayımlanmamış Yüksek Lisans Tezi, Afyon Kocatepe Üniversitesi, Fen Bilimleri Enstitüsü, Afyonkarahisar.

Emniyet Genel Müdürlüğü Trafik Başkanlığı. (2018). İstatistikler. [Çevrim-içi: http://trafik.gov.tr/istatistikler37], Erişim Tarihi: 20 Haziran 2020.

Eygü, H. (2018). Trafik kazalarını etkileyen faktörlerin yapısal eşitlik modeli ile incelenmesi. Elektronik Sosyal Bilimler Dergisi, 17(66), 837-850.

Freydier, C., Berthelon, C. ve Bastien-Toniazzo, M. (2016). Does early training improve driving skills of young novice French drivers? Accident Analysis and Prevention, 96, 228-236.

Glickman, C. D., Gordon, S. P. ve Roos-Gordon, J. M. (2014). Denetim ve ögretimsel liderlik: Gelişimsel bir yaklaşım [Supervision and instructional leadership: A developmental approach ]. (M. B. Aksu ve E. Ağaoğlu, Çev.). Ankara: Anı Yayıncılık.

Güleç, M. A. (2012). Ankara'daki özel sürücü kurslarının performans değerlendirmesi. Yayımlanmamış Yüksek Lisans Tezi, Gazi Üniversitesi, Fen Bilimleri Enstitüsü, Ankara.

Heneman, H. G. ve Milanowski, A. T. (2003). Continuing assessment of teacher reactions to a standards-based teacher evaluation system. Journal of Personnel Evaluation in Education, 17(2), 173-195.

Hicks, H. G. (1979). Örgütlerin yönetimi: Sistemler ve beşeri kaynaklar açısından [The management of organizations: A systems and human resources approach]. (O. Tekok, B. Aytek ve S. Şen, Çev.). Ankara: Turhan Kitabevi.

Jagnoor, J., Sharma, P., Parveen, S., Cox, K. L. ve Kallakuri, S. (2020). Knowledge is not enough: barriers and facilitators for reducing road traffic injuries amongst Indian adolescents, a qualitative study. International Journal of Adolescence and Youth, 25(1), 787-799.

Kazak, E. (2013). Ders denetimindeki uygulama farklılıklarına ilişkin öğretmen görüşleri. Anadolu Eğitim Liderliği ve Öğretim Dergisi, 1(1), 15-26.

Köybaşı, F., Uğulu, C. T., Ağıroplu Bakır, A. ve Karakuş, B. (2017). illkokularda ders denetimine ilişkin öğretmen görüşleri. Turkish Studies, 12(4), 327-344.

Lavigne, A. L. ve Chamberlain, R. W. (2016). Teacher evaluation in Illinois: School leaders' perceptions and practices. Educational Assessment, Evaluation and Accountability, 29(2), 179-209.

Liu, J. (2015). Study on the auditing theory of socialism with Chinese characteristics. New Jersey: John Wiley and Sons.

Liu, S., Xu, X. ve Stronge, J. (2018). The influences of teachers' perceptions of using studentn achievement data in evaluation and their self-efficacy on job satisfaction: evidence from China. Asia Pacific Education Review, 19(4), 493-509.

Lochmiller, C. R. (2016). Examining administrators' instructional feedback to high school math and science teachers. Educational Administration Quarterly, 52(1), 75-109. 
MEB. (2016). Motorlu taşıt sürücüleri kursu rehberlik ve denetim rehberi [Çevrim-içi: http://tkb.meb.gov.tr/meb_iys_dosyalar/2016_11/14010033_motorlu_tasit_suruculeri_kur surehberlik_ve_denetim_rehberi_2016.doc], Erişim Tarihi: 20 Haziran 2020.

Medori, D. ve Steeple, D. (2000). A framework for auditing and enhancing performance measurement systems. International Journal of Operations \& Production Management, 20(5), 520-533.

Özdemir, N. (2020). Principals as instructional leaders: Observation of Turkish and math instruction in lower secondary schools in Turkey. i.e.: inquiry in education, 12(1), 1-18.

Reid, D. B. (2019). What information do principals consider when evaluating teachers? School Leadership \& Management, 39(5), 457-477.

Resmi Gazete (1983). Karayolları trafik kanunu (2918 sayılı Kanun). https://www.mevzuat.gov.tr/MevzuatMetin/1.5.2918.pdf.

Resmi Gazete (2012). Millî Eğitim Bakanlığı Özel Öğretim Kurumları Yönetmeliği (28239 sayılı). https://ookgm.meb.gov.tr/meb_iys_dosyalar/2020_02/25111828_Ozel_Ogretim_Kurumla ri_Yonetmeligi_19022020.pdf.

Reynolds, D., Muijs, D. ve Treharne, D. (2003). Teacher evaluation and teacher effectiveness in the United Kingdom. Journal of Personnel Evaluation in Education, 17(1), 83-100.

Robbins, S. P., Decenzo, D. A. ve Coulter, M. (2013). Yönetimin esasları [Fundamentals of management]. (A. Öğüt, Çev. 8. Baskı). Ankara: Nobel.

Saldaña, J. (2009). The coding manual for qualitative researchers. Thousand Oaks, CA: Sage.

Schildkamp, K., Visscher, A. ve Luyten, H. (2009). The effects of the use of a school selfevaluation instrument. School Effectiveness and School Improvement, 20(1), 69-88.

Selbes, C. (2008). Türkiye'de sürücü eğitimi müfredat programı ile sürücü belgesi alma prosedürünün Avrupa Birliği ülkeleri ile karşılaştırılması. Yayımlanmamış Yüksek Lisans Tezi, Gazi Üniversitesi, Fen Bilimleri Enstitüsü, Ankara.

Stake, R. E. (1995). The art of case study research. Thousand Oaks, CA: Sage.

Süslü, A., Ernas, S. ve Ergören, B. (2020). Türkiye ile Avrupa Birliği ülkelerinin sürücü eğitimleri ve sınav süreçleri bağlamında karşılaştıııması. YILDIZ Journal of Educational Research, 4(1), 101-121.

Timmermans, S. ve Epstein, S. (2010). A world of standards but not a standard world: Toward a sociology of standards and standardization. Annual review of Sociology, 36, 69-89.

Toprakçı, E., Çakırer, I., Bilbay, A., Bagcivan, E. ve Bayraktutan, I. (2010). Kuram ve uygulamada eğitim denetmenleri meslek etiği. Educational Policy Analysis and Strategic Research, 5(1).

Toprakçı, E. (2013). Sınıf yönetimi. Ankara: Pegem.

Toprakçı, E. ve Bakır, D. (2019). Eğitim alanı açısından 10. Kalkınma Planı, 2018 Yılı Programı ve MEB Stratejik Planının uyumluluğunun incelenmesi. Milli Eğitim Dergisi, 48, 103-126.

Turan, F. (2016). Okul öncesi eğitim kurumlarında eğitim öğretim faaliyetlerinin denetimi. International Journal of Eurasia Social Sciences, 7(23), 94-119.

Tuytens, M. ve Devos, G. (2014). How to activate teachers through teacher evaluation? School Effectiveness and School Improvement, 25(4), 509-530.

Tuytens, M. ve Devos, G. (2017). Teacher evaluation policy as perceived by school principals: The case of Flanders (Belgium). Teachers and Teaching, 24(3), 209-222.

World Health Organization [WHO]. (2016). Global status report on road safety. Geneva: WHO.

Xin, T. ve Kang, C. (2012). Qualitative advances of China's basic education since reform and opening up. Chinese Education \& Society, 45(1), 42-50.

Yıldırım, A. ve Şimşek, H. (2011). Sosyal bilimlerde nitel araştırma yöntemleri (8. Baskı). Ankara: Seçkin.

Yin, R. K. (2003). Case study research: Design and methods (3rd Baskı). Thousand Oaks, CA: Sage. 


\section{Standardization Efforts in Inspection: A Sample of Inspection Guide for Motor Vehicle Driving Schools}

\author{
Assoc. Prof. Dr. Nedim Özdemir \\ Ege University-Turkey \\ nedim.ozdemir@ege.edu.tr
}

\author{
Fahri Altuntaş \\ Izmir Provincial Directorate of National \\ Education-Turkey \\ faltuntas44@gmail.com
}

\begin{abstract}
The aim of this research is to examine the consistency of the main sections of the motor vehicle driving school inspection guide according to the relevant literature (educational supervision) and legal regulations. In the study, qualitative research approach was conducted and document analysis technique was used. Accordingly, the document prepared for motor vehicle driving courses was handled among the inspection guides published by the Ministry of National Education to ensure standardization of practice and standardization between the head of the inspectors of education. The data of the research were analyzed according to the document analysis technique. Within the scope of the research, the findings obtained from the inspection guide examined on the basis of legal legislation and literature. According to the findings obtained within the scope of the research, it is seen that the legal document referred to in the majority of the guide has been reached and the statement in the guide coincides with the legal basis. On the other hand, according to the legal basis, there are items that are under-stated in the guide. In addition, it was understood that after the publication of the inspection guide, some changes were made in the regulations but these changes were not reflected in the document. When evaluating from the opening of the literature, it was found that evaluation criteria for some items are not included in the inspection guide. Within the scope of the research, it has been suggested that the Ministry of National Education will reflect the updates to be made in the relevant regulations to the inspection guide.
\end{abstract}

Keywords: Supervision, Inspection Guide, Standards-based Evaluation, Documentary Analysis, Driving School

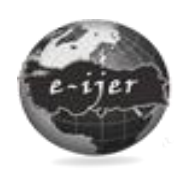

E-International Journal of Educational Research, Vol: 11, No: 3, 2020, pp.79-89

DOI: 10.19160/ijer.807767

Received: 24.10 .2020 Accepted: 08.12.2020

\section{Suggested Citation:}

Özdemir, N. \&. Altuntaş, F. (2020). Standardization efforts in inspection: A sample of inspection guide for motor vehicle driving schools. E-International Journal of Educational Research, Vol: 11, No: 3, 2020, pp. 79-89, DOI: 10.19160/ijer.807767 


\section{EXTENDED ABSTRACT}

Problem: Accountability in education has given a new momentum to reforms that aimed at establishing an effective supervision process (Tuytens ve Devos, 2017). Research provides evidence that supervision is important to increase learning outcomes (Liu, $\mathrm{Xu}$ ve Stronge, 2018; Tuytens ve Devos, 2017). Supervision plays an essential role in achieving the goals of organizations and identifying areas to improve. Supervisors should know what they control, provide useful feedback to the employees, and offer professional learning activities (Özdemir, 2020). However, policymakers and practitioners face some difficulties in planning an audit process. It remains to be discussed as to which of the standards / criteria to be used in auditing reliability and validity and how to use them (Cohen ve Goldhaber, 2016; Heneman ve Milanowski, 2003). Criteria are needed to be handled carefully to ensure unity of practice among auditors and to ensure that the auditor trusts this process. As a matter of fact, with the supervision, it is expected that the existing capacities of the institutions will be improved and their outputs will become more qualified.

Motor vehicle drivers' courses are one of the educational institutions that are inspected. Individuals who have successfully completed these courses are accepted as drivers and allowed to use in road traffic. When the reasons for the occurrence of road traffic accidents are listed, it is seen that one of the most important factors is drivers (Eygü, 2018) Especially the inadequacy of driving skills of drivers under the age of 25 is striking (Freydier vd., 2016). It is expected that the quality of the education offered will increase with the supervision of the courses. Although many studies have been conducted in the literature, no study has been examined regarding the inspection of motor vehicle driving courses. In this study, the document prepared by the Ministry of National Education (MoNE) to ensure the unity and standardization of implementation between the departments of education inspectors was examined. This guide was published in 2016 and it was emphasized in the introduction that it should be updated in the following years. Accordingly, it is necessary to evaluate the inspection criteria in the current document on the basis of legal documents and literature. It is expected to contribute to policy makers and practitioners in line with the existing research and suggestions for the improvement of the inspection guide.

Method: In this study, qualitative research approach was done and document analysis technique was used. This technique aims to systematically examine printed or electronic materials that are closely related to the research problem (Bowen, 2009; Yıldırım ve Şimşek, 2011). The Ministry of National Education has published 16 different audit guides under the supervision of schools, institutions and units. In the present study, the guidance used for the supervision of the Motor Vehicle Courses were examined. The first part of this guide contains the aim, scope and basis title. Then, the principles and principles of guidance and supervision, respectively, and the reporting standards in the last section. For the reporting standards, there were eight sub-headings: firstly, the introduction, followed by education and training activities, management activities, financial affairs and operations, monitoring and evaluation, management information, sample practices and general evaluation (Ministry of Education Guidance and Inspection Presidency, 2016).

The research data were analyzed in accordance with the document analysis technique. The titles and sub-titles in the Guide, which were used in the research, were transferred to the Microsoft Excel program. As a result of this process, it was seen that there were 100 items in the audit guide. Each item used in the audit guide has been added on a line in the Excel sheet. In addition, the legal beatings cited in the guide were accessed on the Internet and added next to each criterion. A third column was used to compare the items in the audit guide with the literature. In the last column of the table where the data is processed, the legal basis of the 
items and the literature are compared. Codes were used for this comparison and categories were created with the combination of codes. Finally, the codes and categories are classified under two themes: legal basis and literature. In order to determine the codes used within the scope of the study, a common framework was determined with the researchers who examined the guidance and supervision guides of other schools / institutions. However, additions were made to the codes during the implementation process (Saldaña, 2009).

Researchers first assigned codes for each item included in the audit guide. In this context, the codes "the referenced legal document is reached" and "the statement in the guide coincides with the legal basis" are grouped under the "consistency with legal basis" category. Similarly, the codes "article number does not match in the referenced legal document" and "the legal basis for which is sent is not expressed correctly" are categorized as "stating the legal basis incorrectly". With the combination of both categories, the theme of "comparing the consistency between audit and legal regulations" has been reached. In addition, the sections where the codes are included in the document are shown with symbols. In this study, different methods were used to increase validity and reliability in the process of data collection and analysis (Yıldırım ve Şimşek, 2011).

Findings: According to the findings obtained within the scope of the study, it was observed that the legal document referred to in the majority of the inspection guide prepared for motor vehicle drivers' courses was reached and the statement in the guide and the legal basis coincided. In this respect, it can be said that the guide is guiding the inspection process in terms of the relevant legal documents and is correction-development oriented. On the other hand, in the present study, some items were expressed incompletely according to the legal basis. This situation obliges both the inspectors and the staffs to consult the legal document together with the guide. The use of more than one document can create problems for practitioners and prevent standardization in inspection process. Another finding showed that although changes were made in some legal documents, the inspection guide was used as it was in 2016. Also, some aspects of the inspection guide were consistent with the literature. There are evaluation criteria in many items in the guide. In this way, the inspector can compare and evaluate the measurement result according to a criterion. However, some items in the inspection guide did not have evaluation criteria. In order to arrive at an evaluation, the measured feature must be compared according to a criterion. Also, the features to be measured were re-examined within different items. The inspection guide was created without referring to the literature within the scope of the present study.

Suggestions: Some suggestions have been developed based on the research findings. When creating an inspection guide, the principle of usefulness should be taken into consideration and it should be ensured that it is prepared in a way that fully includes the legal legislation. The preparation of the auditors and auditees using the audit guide over a single document can prevent reciprocity. It can be ensured that the audit guide is dynamically designed in the digital environment and associated with the regulations to be sent. Although its importance is emphasized in the literature, another issue that is not included in the inspection guide is that self-evaluation activities cannot be included. Regulations should be made to encourage selfevaluation studies in terms of institutional development. 